\title{
THE IMMUNOMODULATORY EFFECTS OF SUTHERLANDIA FRUTESCENS EXTRACTS IN HUMAN NORMAL PERIPHERAL BLOOD MONONUCLEAR CELLS
}

\author{
Mlungisi Ngcobo ${ }^{\mathrm{a}, \mathrm{b}}$, "Nceba Gqaleni ${ }^{\mathrm{b}}$, Paul K. Chelule ${ }^{\mathrm{d}}$, Metse Serumula ${ }^{\mathrm{a}}$ and Alain Assounga ${ }^{\mathrm{c}}$
}

${ }^{\mathrm{a}}$ Mycotoxin Research Unit, School of Medical Sciences, Faculty of Health Sciences, ${ }^{\mathrm{b}}$ South African Research Chair: Indigenous Health Care Systems, University of KwaZulu-Natal Durban, South Africa. ${ }^{\mathrm{c}}$ Department of Nephrology, Nelson R Mandela School of Medicine, University of KwaZulu-Natal Durban, South Africa. ${ }^{\mathrm{d}}$ Department of Occupational and Environmental Health, Nelson R Mandela School of Medicine, University of KwaZulu-Natal

*E-mail: gqalenin@ukzn.ac.za

\begin{abstract}
Sutherlandia frutescens (SF) is one of the medicinal plants used as an immune booster in the treatment of chronic ailments such as HIV/AIDS and cancer. Limited data suggest that its efficacy is based on its regulatory effect on cytokines, the critical components of the immune response. In this study, we investigated the in vitro immunomodulatory effects of SF extracts on normal human peripheral blood mononuclear cells (PBMCs). An ELISA-based assay was used to assess the levels of expression of 12 cytokines in treated cells. An adenosine triphosphate (ATP) assay was used to assess cell viability in relation to cytokine secretion. SF ethanol extracts induced changes in cytokine secretion relative to the dose of the extract. Generally cytokine expression and secretion was low in concentration because were not stimulated with any endotoxin. The high SFE dose $(2.5 \mathrm{mg} / \mathrm{ml})$ significantly $(p<0.001)$ decreased some cytokines including TNF- $\alpha$ and IL $1 \beta$. Low doses of this extract $(0.5 \mathrm{mg} / \mathrm{ml})$ did not change TNF- $\alpha$ and IL $1 \beta$ secretion from the baseline (untreated cells). Changes in cytokine secretion of SFE treated cells tracked changes in ATP levels (cell viability). The SFW extract-induced changes in cytokine secretion were independent of cell viability. TNF- $\alpha$ was decreased $(p<0.001)$ by the high dose of SFW extract while IL $1 \beta$ and IFN $\gamma$ were increased $(p<0.01)$ by the same dose. High doses decreased cell viability which was reflected in cytokine secretion. It is evident, from these results, that SF extracts can modulate cytokine secretion in unstimulated normal PBMCs in vitro. Further studies in animal models are recommended to advance understanding of this immunomodulatory activity.
\end{abstract}

Keywords: immune response, Sutherlandia frutescens, cytokines, ELISA, cell viability

\section{Introduction}

The use of African traditional medicine (ATM) in southern Africa has been shown to be on the rise as a result of the high prevalence of HIV/AIDS, tuberculosis (TB), malaria, cancer, diabetes and hypertension (Chabalala, 2008). The progression of these diseases is more rapid in patients with compromised immune system. One of the ATMs, Sutherlandia frutescens (SF) (Insizwa/Unwele in Zulu, or Cancer bush), is regarded as the most profound and multi-purpose medicinal plant in Southern Africa (Sia, 2004). Traditional healers usually prepare decoctions of SF according to the type of ailment pointed out by the patient. The preparation ranges from using each part of the plant alone (leaves, flowers, stems and roots) to using mixtures of these parts (van Wyk et al., 1997, van Wyk, 2008). Commercial preparations of SF have circumvented the need for preparing a mixture of the plant material with all the plants parts known to have active ingredients.

Sutherlandia frutescens is postulated to act as an immunotonic and a supplement which assists the body in mobilizing its own immune response to fight infections and cope with mental stress. Despite its broad spectrum of applications, not enough reports have been published on the efficacy of this plant in fighting diseases as claimed by the healers (Mills et al, 2005). It is known for its efficacy and safety for use in many different health conditions (MRC, 2001; Johnson et al., 2007). Anecdotes have been provided from different clinical settings on how SF preparations improved the well-being and $\mathrm{CD} 4^{+}$cell counts in HIV/AIDS patients; and of how taking preparations of SF (commercial tablets, tea formulations, medicinal preparations from healers, etc) have greatly improved the well-being and $\mathrm{CD} 4^{+}$counts of HIV/AIDS sufferers (Jenkins, 2005). Tai et al. (2004) did not find any significant changes in secretion of cytokines (IL $1 \beta$ and TNF $\alpha$ ) caused by SF ethanol extracts in murine macrophage/monocytes RAW 264.7 cells. Cytokine secretion/expression is thought to play an important role in disease development and/or progression, especially in HIV/AIDS and cancer patients.

Interleukin 1 is primarily produced by cells of the mononuclear phagocytic lineage but is also produced by oestoblasts, neutrophils, glial cells, and numerous other cells. One of the most important biological activities of IL 1 is its ability to activate T lymphocytes by enhancing the production of IL 2 and expression of IL 2 receptors. Interleukin 1 augments B cell proliferation and increases immunoglobulin synthesis (Borish and Steinke, 2003). Interleukin 4 is an antiinflammatory cytokine that down-regulates both the innate and the adaptive immune responses. It is mainly produced by $\mathrm{T}$ cells, NK cells and mast cells and targets other T cells, eosinophils and endothelial cells for its regulatory actions (Alfano and Poli, 2005). Interleukin 6 is a key growth-promoting and anti-apoptotic inflammatory cytokine and is one of the effector signals of activated NF-қB in the promotion of neoplasia (Germano et al., 2008). Interleukin 8 is one of the most important chemo-attractants of neutrophils and its synthesis is enhanced by IL 1 (Borish and Steinke, 2003). Intereukin 10 inhibits the production of all pro-inflammatory cytokines and chemokines and the expression of dendritic cells co-stimulatory molecules, therefore shutting-off T-cell activation. Interleukin 10 levels have been found elevated in lymph nodes of HIV-infected individuals (Alfano and Poli, 2005). Tumour necrosis factor- $\alpha$ interacts with endothelial cells to induce adhesion molecules 
known as intracellular adhesion molecule (ICAM)-1, vascular adhesion molecule (VCAM)-1, and E-selectin, thus permitting accumulation of granulocytes into inflammatory sites. Its pro-inflammatory actions allow for tumour regression by host immune reaction and inhibition of tumour angiogenesis (Minuzzo et al., 2007).

The main aim of our study was to assess the immunomodulatory effects of SF ethanol and water extracts on normal human peripheral blood mononuclear cells (PBMCs). We achieved this by analysing the levels of cytokines and chemokines secreted by these cells in vitro. An ELISA-based multi-analyte assay was used to analyse for the secretion of a panel of twelve different cytokines (IL $1 \alpha$, IL $1 \beta$, IL 2, IL 4, IL 6, IL 8, IL 10, IL 12, IL 17 $\alpha$, IFN- $\gamma$, TNF- $\alpha$, and GM-CSF). The relationship between these cytokine effects and PBMCs viability was also investigated using a luminometry based ATP assay.

\section{Materials and Methods \\ Reagents and equipment}

RPMI-1640 with HEPES buffer (25mM), foetal calf serum (FCS), penstrep-fungizone (PSF), and L-glutamine were purchased from Adcock Ingram (SA). Normal whole blood was obtained from the South African National Blood Supply (SANBS). Histopaque 1077 was purchased from Sigma Aldrich (SA). Ethanol was bought from Merck Chemicals (SA). Promega CellTiter-Glo ${ }^{\mathrm{TM}}$ Luminescent Cell Viability was purchased from Promega (SA). Sutherlandia frutescens tablets were bought from the local Chemist (Durban- SA). The Multi-Analyte Profiler ELISArray ${ }^{\mathrm{TM}}$ Kit was purchased from SABiosciences (USA). Modulus ${ }^{\mathrm{TM}}$ Microplate Luminometer was from Turner BioSystems (USA). The 96-well plate reader was acquired from Bio-Tek (SA).

\section{Extraction of active ingredients from Sutherlandia frutescens tables}

Each of the SF tablet was extracted according to the method of Tai et al., (2004) with a slight variation. Briefly, SF tablets containing $300 \mathrm{mg}$ of raw herb powder (per tablet) compounded with inert excipients were extracted with $2.2 \mathrm{ml}$ of $70 \%$ ethanol/triple distilled water at room temperature for 2 hours on an orbital shaker. The suspension was then centrifuged at $2000 \mathrm{~g}$ for 10 minutes and the supernatant was removed. The extracts were filter-sterilised twice using $0.45 \mu \mathrm{m}$ filters to give a stock solution of $136.4 \mathrm{mg} / \mathrm{ml}$ of each extract type. These extracts were further serially diluted to $2.5,1.5,0.5$ and 0.25 $\mathrm{mg} / \mathrm{ml}$ with complete culture medium (RPMI-1640 supplemented with 10\% FCS, $1 \%$ L-glutamine, and 1\% PSF). Both types of extracts were prepared on the same day of use.

\section{Isolation of peripheral blood mononuclear cells (PBMCs) from whole blood}

Normal whole blood from healthy volunteers (acquired from the SANBS in lithium heparin coated containers, ethics approval number EXP057/06) was carefully layered onto equal amounts of Histopaque 1077 then centrifuged at $400 \mathrm{~g}$ for 30 minutes at $25{ }^{\circ} \mathrm{C}$. After centrifugation, the buffy coat layer, containing PBMCs, was isolated and washed twice in phosphate buffered-saline (PBS, $5 \mathrm{ml}),\left(1150 \mathrm{~g}\right.$ for 20 minutes at $\left.25{ }^{\circ} \mathrm{C}\right)$. The isolated PBMCs were diluted in RPMI-1640 and pooled into one tube. A cell count of $1.5-2 \times 10^{6}$ cells $/ \mathrm{ml}$ was determined using the trypan blue method to standardise the cell dilution.

\section{Treatment of PBMCs with Sutherlandia frutescens extracts}

Aliquots of the cell suspension $\left(2 \mathrm{ml}-4 \times 10^{6}\right.$ cells $)$ were transferred into each well in a 6-multiwell plate. Doses of $\mathrm{SF}$ extracts $(2 \mathrm{ml})$ were then added to each of the treatment wells. Vehicle control $(70 \%$ ethanol) for the ethanol extract of SF, phytohaemagglutinin (PHA- $10 \mu \mathrm{g} / \mathrm{ml}$ ) camptothecin (CPT, $20 \mu \mathrm{M}$ ) and untreated control wells were also included in the treatment setup as method controls. The 6-well plates were then incubated for 24 hours at $37^{\circ} \mathrm{C}$ in a $5 \% \mathrm{CO}_{2}$ incubator.

\section{Cytokine secretion assay}

The Multi-Analyte Profiler ELISArray assay kit (SA Biosciences, cat number: MEH-004A) is designed to be used with supernatants from treated cells or with serum from whole blood. It is a variation of the normal ELISA kit which uses absorbance instead of fluorescence to read the final results. The kit also does not give the exact concentration of each cytokine in pico or nanograms as a normal ELISA kit but differences in absorbance readings between controls and treated samples gives changes in cytokine secretion. For the purpose of this research, cytokines were analysed from supernatants of treated PBMCs. Each kit included 96-well plate coated with antibodies for the various cytokines in the microarray. Each row of the plate from 1 to 12 represented a single cytokines in the following order: IL $1 \alpha$, IL $1 \beta$, IL 2, IL 4, IL 6, IL 8, IL 10, IL 12 , IL $17 \alpha$, IFN- $\gamma$, TNF- $\alpha$, and GM-CSF. The kit had negative and positive method controls. Each sample was assayed in duplicate.

Briefly, incubation of the samples in the 96-well plates allowed the capture antibodies to bind their specific protein of interest. After washing away unbound protein with wash buffer, biotinylated detection antibodies $(50 \mu 1)$ were added to the wells to also bind the captured analyte. Following another wash, an avidin-horseradish peroxidase conjugate $(100 \mu l)$ was added. The wells were again washed and the colorimetric substrate solution was added, developing to a blue colour in direct proportion to the amount of protein analyte present in the initial sample. The colour development was stopped by adding the stop solution, and the absorbance was read at $450 \mathrm{~nm}$ with reference at $570 \mathrm{~nm}$ in a microplate reader as per manufacturer's instructions. 


\section{Cell viability assay}

Following the incubation of treated cells for 24 hours, a $100 \mu$ sample from each treatment concentration was pipetted into three different wells of a white opaque 96-well plate. The CellTiter-Glo ${ }^{\mathrm{TM}}$ Reagent (Promega, cat number: G7570) was mixed immediately before use and was added to the wells with treated cells at $25 \mu 1$ per well. The plate was shaken on a plate shaker for 2 minutes at $30 \mathrm{~g}$. This plate was then incubated in the dark for 10 minutes at room temperature and the relative light units (RLU) of the samples were measured in a luminometer following the manufacturer's instructions. A dose response curve was also generated for the ATP levels using the RLU and the dilutions of SF extracts and different control samples.

\section{Statistical analysis}

Data analyses were done on Microsoft Excel (Microsoft Corporation, City, USA) to obtain descriptive statistics. The different levels of significances within the separate treated groups were analysed using one-way analysis of variance (ANOVA) and the differences between the treated cells and the control cells (baseline) were analysed using GraphPad Instat software (version 3 ) with the Tukey-Kramer multiple comparison test. Differences with $p \leq 0.05$ were considered statistically significant.

\section{Results \\ Cytokine expression}

Although these cytokines were expressed at low concentrations in all samples, the mean cytokine concentrations in the treated samples and the controls were statistically significant (Figures 1-3). Interleukin $1 \alpha$ levels decreased significantly in CPT treated supernatants $(p<0.001)$ and were unchanged in PHA treated samples $(p>0.05)$. IL $1 \alpha$ levels were unchanged in SFE extract doses while it was significantly increased in the $2.5 \mathrm{mg} / \mathrm{ml} \mathrm{SFW}$ dose $(p<0.001)$ as compared to the untreated control. The secretion of IL $1 \alpha$ was higher in SFW extract doses than in the SFE extract doses. A similar response was observed in IL $1 \beta$ cytokine secretion although its concentration was higher relative to the others assayed in this group (Figure 1). Expression of IL 2 in all control samples and SF extract treated samples did not show any significant changes $(p>0.05)$ (Figure 1). Interleukin 4 concentrations were unchanged in SF extract (SFE or SFW) treated samples when compared with the untreated control samples. The SFE extracts decrease IL 4 levels while this cytokine's secretion did not change $(0.5$ $\mathrm{mg} / \mathrm{ml})$ or increased $(2.5 \mathrm{mg} / \mathrm{ml})$ in the SFW extracts. However all these effects were not statistically significant $(p>0.05)$. Phytohaemagglutinin significantly increased $(p<0.001)$ IL 4 levels compared to all the various samples and controls (Figure $1)$.

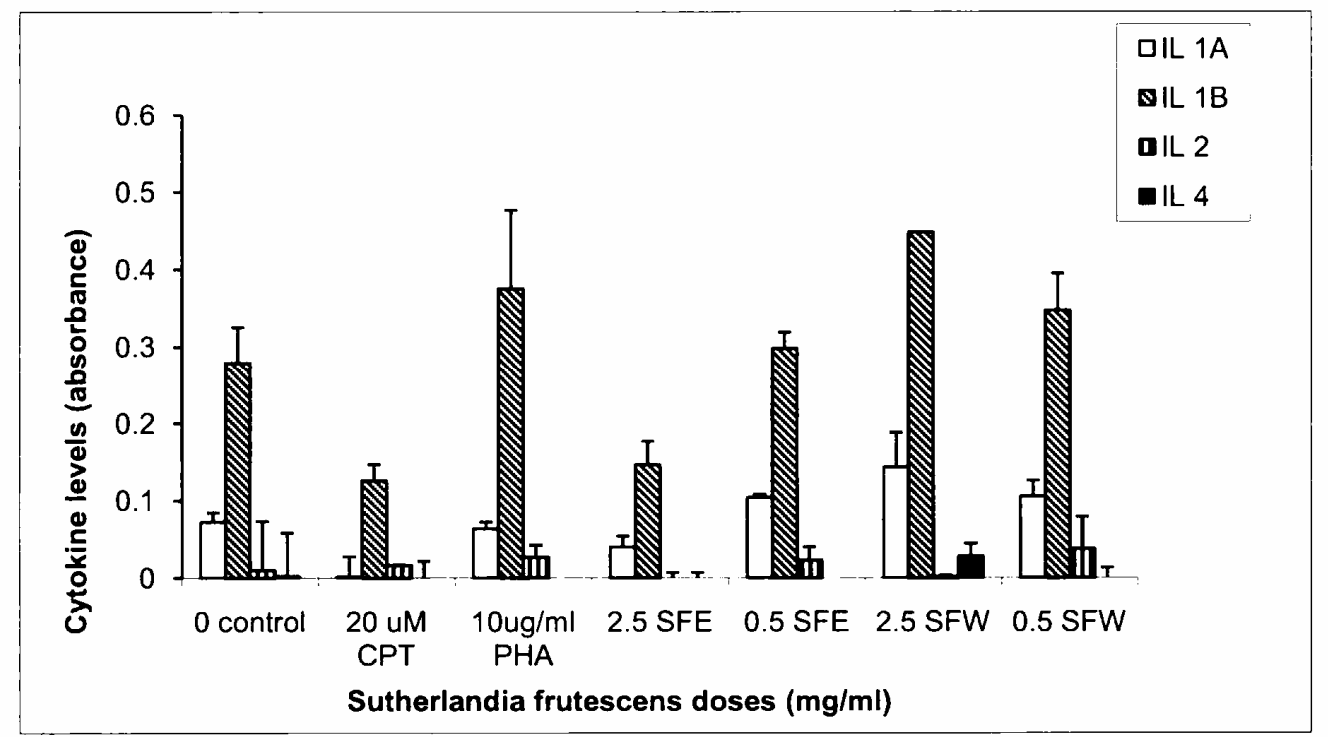

Figure 1: Graphical illustration of changes in secretion of interleukins $1 \alpha, 1 \beta, 2$ and 4 in controls and Sutherlandia frutescens extracts treated samples. An ELISA-based kit was used to measure secretion of cytokines in cell supernatants and the results were obtained by measuring absorbance at $450 \mathrm{~nm}$ using a plate reader. The SFW doses increased the secretion of IL $1 \alpha \& 1 \beta$ while the high dose of SFE decreased both cytokines. A high dose of SFW also increased IL 4 secretion. In contrast, the secretion of all 4 cytokines was decreased in CPT treated cells, while PHA either showed no change or increased levels of all 4 cytokines. 


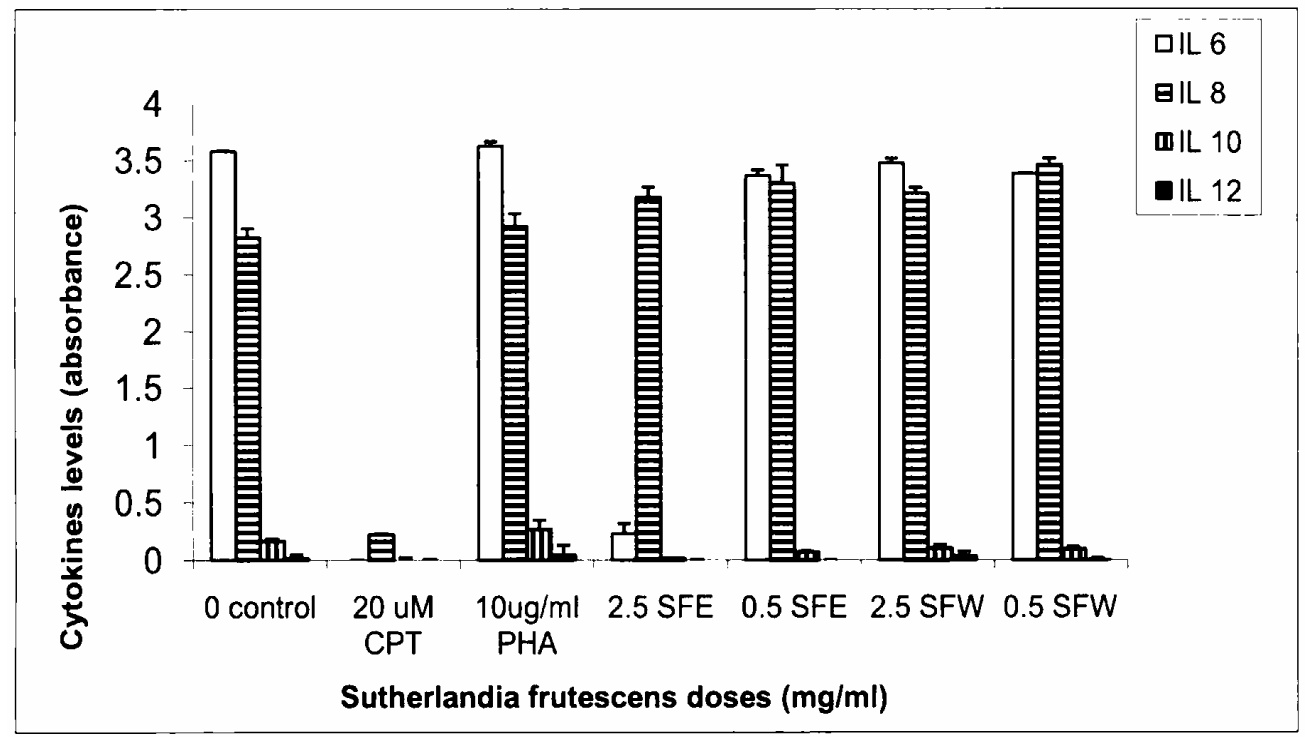

Figure 2: Changes in secretion of IL 6, IL 8, IL 10, and IL 12 in controls and Sutherlandia frutescens extract dilutions treated samples. SF extracts decreased levels of IL 6 in all treated samples while similarly increasing the secretion of IL 8. A high dose of the SFE extract $(2.5 \mathrm{mg} / \mathrm{ml})$ significantly decreased IL $10 \& 12$ secretion. Both SFW doses showed a decrease in IL 10 secretion. All cytokines were significantly decreased in the CPT treated samples while PHA did not change levels of any of these cytokine.

Interleukin 6 concentrations in supernatants of all SF extract treated cells were significantly decreased when compared to the controls, with the SFE extracts being more effective in decreasing their secretion $(p<0.001)$ than SFW extracts $(p<0.01)$ (Figure 2). Interleukin 8 concentrations were significantly increased in all SF extracts treated samples $(p<0.001)$ when compared to the control samples. SFE extract significantly reduced $(p<0.001)$ and SFW extracts slightly $(p<0.01)$ reduced IL 10 secretion when compared to the untreated control. Concentrations of IL 12 did not change in either control or SF extract treated samples $(p>0.05)$ (Figure 2).

High doses of both SF extracts $(2.5 \mathrm{mg} / \mathrm{ml} \mathrm{SFE}$ and SFW) significantly reduced the secretion of TNF- $\alpha$ in supernatants of treated PBMCs $(p<0.001)$. The low doses also decreased TNF- $\alpha$ levels but this was not statistically significant $(p>0.05)$. The levels of IFN- $\gamma$ in SFE extract treated samples were unchanged while the SFW extract doses increased the secretion of this cytokine $(p<0.01)$ (Figure 3). The lower dilutions of the SF extracts reduced GM-CSF levels, but not significantly $(p>0.05)$ while the higher dilutions increased IL 17A (not significant, $p>0.05$ ).

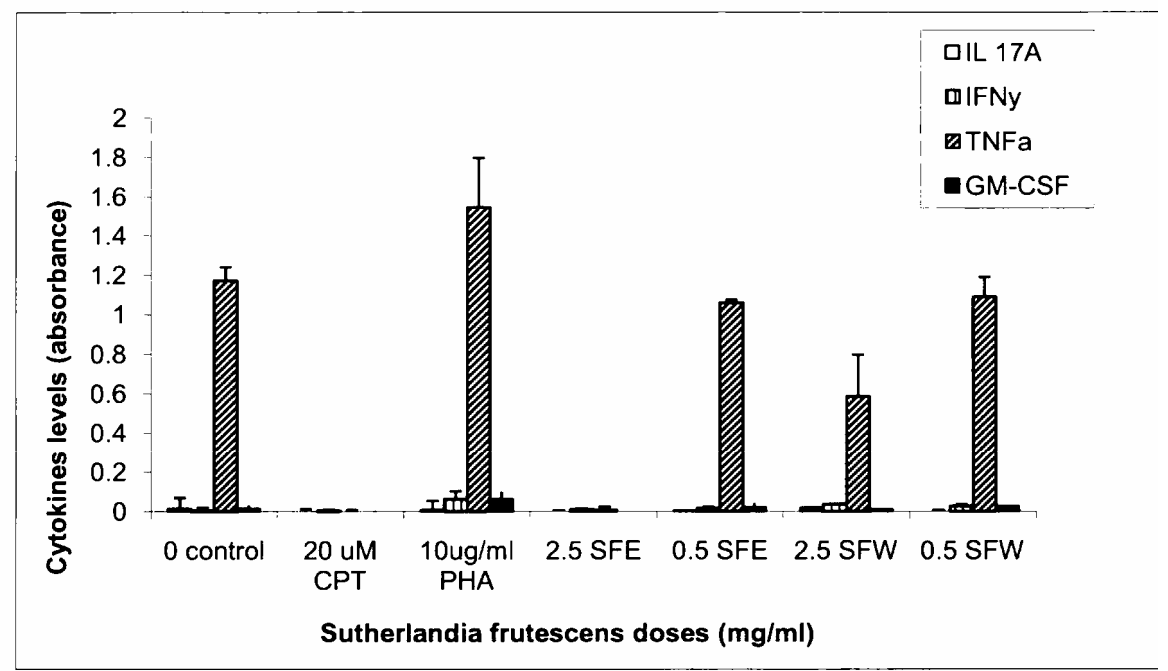

Figure 3: Changes in the secretion of IL $17 \alpha$, IFN $\gamma$, TNF- $\alpha$, and GM-CSF in controls and Sutherlandia frutescens extract dilutions treated samples. CPT treated samples significantly decreased all cytokines while PHA samples showed an increase in all cytokines. High dose of SFE $(2.5 \mathrm{mg} / \mathrm{ml})$ significantly decreased all cytokines but also caused increased cytotoxicity in PBMCs. SFW extracts decreased TNF- $\alpha$ secretion without the excessive cytotoxicity shown by the ethanol extract of SF. The SFW extract doses also increased secretion of IFN- $\gamma$, an important cytokine in fighting viral infections. 


\section{Changes in cell viability relative to cytokine expression}

ATP assay was performed to determine the cytotoxicity of SF extracts on the treated cells. Peripheral blood mononuclear cells treated with the camptothecin $(20 \mu \mathrm{M})$ had significantly reduced ATP levels $(51 \%)$ when compared to theuntreated control cells $(p<0.001)$. The positive control (PHA, $10 \mu \mathrm{g} / \mathrm{ml})$ significantly increased ATP levels $(161 \%)$ over the 24 hours $(p<0.001)$. The $70 \%$ ethanol vehicle control was not included in the cytokines analyses setup because it does not change the ATP levels (97\%) when compared to the untreated PBMCs ( $p>0.05)$ (Figure 4). The ethanol used for extraction did not play any statistically significant role in the effects of SFE extract dilutions on ATP levels in treated PBMCs. The high dose of the SF extracts $(2.5 \mathrm{mg} / \mathrm{ml}$ SFE and SFW) significantly $(p<0.001)$ reduced the cell viability $(25 \%$ and $60 \%$, respectively) from the untreated baseline control. The $2.5 \mathrm{mg} / \mathrm{ml} \mathrm{SFE}$ extract dose was more potent in reducing ATP levels than CPT $(p<0.001)$. The low dose of the SFE extract $(0.5 \mathrm{mg} / \mathrm{ml})$ significantly decreased the ATP levels $(p<$ 0.01 ). The $0.5 \mathrm{mg} / \mathrm{ml} \mathrm{SFW}$ dose did not significantly change ATP levels (Figure 4). These results demonstrate increased cytotoxicity of higher doses of SF extracts on cultured normal PBMCs in vitro.

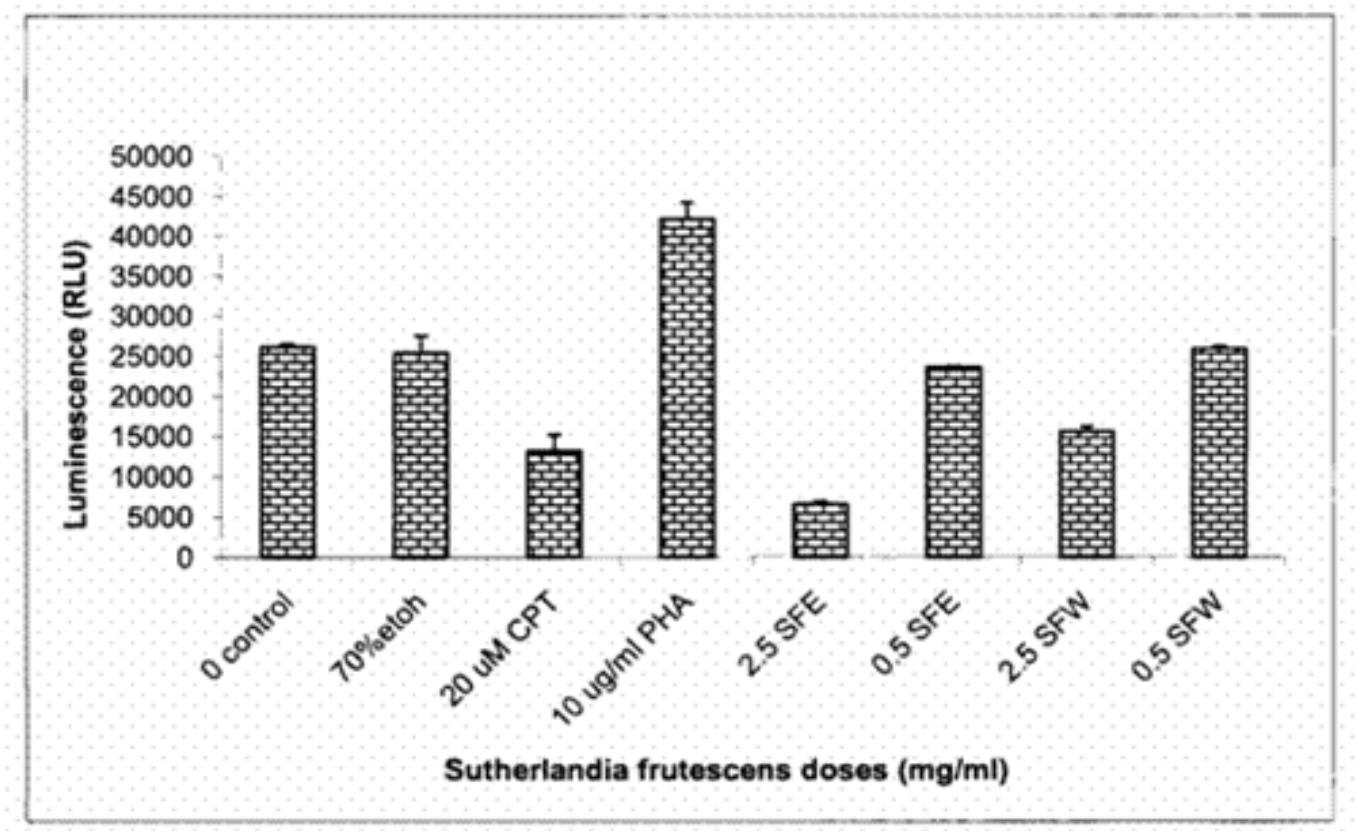

Figure 4: Changes in cell viability of PBMCs treated with various doses of Sutherlandia frutescens extracts (SFE and SFW) over 24 hours. Conversion of the luminescence readings into a percentage cell viability change against the negative control showed that the high doses $(2.5 \mathrm{mg} / \mathrm{ml})$ of the SFE \& SFW extracts induced a very significant decrease in cell viability. A low dose $(0.5 \mathrm{mg} / \mathrm{ml})$ of SFE induced a slightly significant decrease in ATP while the same SFW dose was not significant. It was also shown that the actions of the SFE extract doses were independent of ethanol ( $70 \%$ ethanol). PHA induced a significant increase in ATP levels while CPT decreased ATP levels significantly $(p<0.001)$

\section{Discussion}

A study by Hendricks and Pool (2010) on the effects of Rooibos tea on immune cells showed that cytokines are expressed at very low concentrations in unstimulated immune cells while stimulation with endotoxin lipopolysaccharide (LPS) dramatically increase cytokine expression. This study was done on unstimulated PBMCs and therefore in agreement with above mentioned study on Rooibos tea. The results of this study have demonstrated that SF extracts can modulate cytokine expression in unstimulated treated PBMCs in vitro. The immunomodulatory ability of these SF extracts was dependent on the dose and type of the extract used. Cytokine secretion was also related to the cell viability. The chemical composition analyses of commercially available tablets of SF extracts has shown that this medicinal plant comprise several biological active compounds including L-canavanine, pinitol, gamma-aminobutyric acid, methyl- and propyl parabens and saponins, flavonol glycosides, triterpenoid saponins but no alkaloids (Tai et al., 2004; Stander et al., 2009; van Wyk and Albrecht, 2008). Triterpenes are regarded as role players in the mechanism of action and pharmacological effects of many medicinal plants used against diseases in which the immune system is implicated. They are regarded as having antiinflammatory and immunomodulator compounds (Rios, 2010).

Sutherlandia frutescens efficacy is demonstrated when it upregulates the secretion of IL 1 and IL 2. Interleukin 2 production has been shown to be deficient in HIV infected individuals as well as after in vitro infection of PBMCs with HIV. 
Due to the short half-life of IL 2, changes in the levels of this cytokine are not easy to assay directly (Alfano and Poli, 2005). One of the most important biological activities of IL 1 is its ability to activate T lymphocytes by enhancing the production of IL 2 and secretion of IL 2 receptors (Borish and Steinke, 2003). These findings support the notion that higher doses of SF extracts, which tend to reduce secretion of IL 1 cytokines, may suppress the immune response and its anti-inflammatory purpose. However, in our study the low doses of SF extracts which enhanced IL 1 cytokine secretion and therefore can be expected to stimulate the immune response.

The increased secretion of IL $1 \beta$ caused by the SFW extract contradict the results obtained by Tai et al., (2004). They found that there was no significant change or inhibition of IL $1 \beta$ expression in RAW 264.7 macrophage cells treated with dilutions of an ethanol extract of SF. Although the experimental conditions were not similar, results in this current study demonstrate that SFW doses can increase IL $1 \beta$ secretion. This pro-inflammatory cytokine, along with TNF- $\alpha$, has been implicated in the cachexia seen in patients with HIV/AIDS. Agents that can reduce their production are thought be clinically useful. It was also observed that high doses of SFE extracts can reduce the levels of IL $1 \beta$. The high SF doses also lowered the cell viability and therefore, could have negatively affected the IL $1 \beta$ secretion. A dose-response assessment may be required to determine the right dose that gives the desired effects as demonstrated previously (Fernandes et al., 2004 and Kundu et al., 2005).

The ability of SF extract dilutions to significantly decrease the levels of IL 6 may be a good indicator of SF efficacy. Interleukin 6 is a key growth-promoting and anti-apoptotic inflammatory cytokine and is one of the effector signals of activated nuclear factor- kappa (NF-қB) in the promotion of neoplasia (Germano et al., 2008). Depending on the type of cancer model, IL 6 activates different major pathways of cell proliferation, inducing tumour growth, metastasis, and resistance to chemotherapy (Salazar-Onfray et al., 2007). Therefore a decrease in this cytokine might negatively affect growth and metastasis of cancerous cells.

The current study also demonstrated that SF extracts can suppress the secretion of IL 10. This activity may result in the activation of T-cells and thus, the reduction of HIV replication. Increased levels of IL 10 inhibit the production of all pro-inflammatory cytokines and chemokines and the expression of dendritic cell-co-stimulatory molecules, therefore shutting-off T-cell activation (Alfano and Poli, 2005). Thus, the suppressing effect of SF on IL 10 is a positive indicator of SF extract efficacy. SF extracts, especially the SFW extract doses, increased the secretion of IFN $\gamma$ in treated PBMCs regardless of dose level used. IFN $\gamma$ is an important cytokine in the immune system's response against viral infections (Parkin and Cohen, 2000). Thus, enhanced production of IFN $\gamma$ stimulated by SF may be postulated as playing a role in reducing infections such as HIV.

Analysis of ATP levels was aimed at ascertaining whether cell viability had a role in the changes in the expression of cytokines in PBMCs. Some of the cytokines were up-regulated (i.e. IL $1 \alpha \& 1 \beta$, IL 2, IL 8 and IFN $\gamma$ ) above or maintained to the levels of the untreated controls while ATP levels were shown to be depleted by high doses of the SF extracts (Figures $1,2,3 \& 4$ ). These observations show that cytotoxicity (changes in ATP concentrations) of the SF extract doses was not directly related to the amount of cytokines secreted by the treated PBMCs. A possible exception to this would be the cells treated with the $2.5 \mathrm{mg} / \mathrm{ml} \mathrm{SFE}$ extract dose. These cells secreted low levels of cytokines generally consistent with the decrease cell viability of treated PBMCs.

A number of studies have shown the cytotoxicity of SF extracts on cultured cell lines in vitro (Tai et al., 2004; Chinkwo, 2005; Stander et al., 2009; Korb et al., 2010). L-canavanine, a natural L-arginine analogue, and its metabolite canaline were suggested as two of many factors contributing to in vitro antiproliferative and apoptotic activity of SF extracts (Chinkwo, 2005). Although our current study did not identify the exact active ingredients found in the SF tablet used in this study, it is postulated that the same ingredients could elicit the similar effects observed in the PBMCs as demonstrated by the luminometry ATP assay.

\section{Conclusion}

This study has shown that SF ethanol and distilled water extracts can modulate the expression of pro-inflammatory cytokines in treated PBMCs in vitro. High doses of SFE extract reduced secretion of IL $1 \alpha$, IL $1 \beta$ and TNF- $\alpha$ in treated PBMCs. The cell viability assay showed that extracts of SF can be cytotoxic to isolated lymphocytes and therefore negatively affect cytokine secretion. The results of this study warrant further investigation and animal studies are recommended to further elaborate our findings.

\section{Acknowledgements}

This study was supported by funding from the National Research Foundation (NRF) through Professor Nceba Gqaleni. We would also like to thank the South African National Blood Service (SANBS) for supplying us with research blood samples from their limited stocks.

\section{References}

1. Alfano, M., Poli, G. (2005). Role of cytokines and chemokines in the regulation of innate immunity and HIV infection. Mol. Immunol. 42: 161-182.

2. Borish, L.C., Steinke, J.W. (2003). Cytokines and chemokines. J. Allergy Clin. Immunol. 111: 460-475. 
3. Chabalala, H. (2008). African Traditional Medicines: The Role of Indigenous Knowledge Systems in Bioprospecting and Product Development in South Africa. Paper as presented at the 2008 Rebuild Africa Conference, Washington DC. August 8-9.

4. Chinkwo, K.A. (2005). Sutherlandia frutescens extracts can induce apoptosis in cultured carcinoma cells. J. Ethnopharmacol. 98: 163-170.

5. Fernandes, A.C., Cromarty, A.D., Albrecht, A., van Rensburg, C.E. (2004). The antioxidant potential of Sutherlandia frutescens. J. Ethnopharmacol. 95: 1-5.

6. Germano, G., Allavena, P., Mantovani, A. (2008). Cytokines as a key component of cancer-related inflammation. Cytokine 43: 374-379.

7. Hendricks, R., Pool, E.J. (2010). The in vitro effects of Rooibos and Black tea on immune pathways. J. Immunoassay Immunochem. 31: 169-180.

8. Jenkins, C. (2005). Herbs yield results with AIDS patients. Mercury, July 6: pg 6.

9. Johnson, Q., Syce, J., Nel, 1 H., Rudeen, K., Folk, W.R. (2007). A randomized, double-blind, placebo-controlled trial of Lessertia frutescens in healthy adults. PLoS Clin. Trials 2: e16.

10. Korb, V.C., Moodley, D., Chuturgoon, A.A. (2010). Apoptosis-promoting effects of Sutherlandia frutescens extracts on normal human lymphocytes in vitro. S. Afr. J, Sci., 106 (1/2): 64-69.

11. Kundu, K.K., Mossanda, K.S., Na, H.K., Surh, Y.J. (2005). Inhibitory effects of extracts of Sutherlandia frutescens (L.) R. Br. and Harpagophytum procumbens DC on phorbol ester-induced COX-2 expression in mouse skin: AP-1 and CREB as potential upstream targets. Cancer Lett. 218: 21-31.

12. Medical Research Council (MRC), National Research Foundation (NRF) of South Africa, (2002). A toxicity study of Sutherlandia leaf powder (Sutherlandia microphylla) consumption. Final Report (report available on the internet).

13. Mills, E., Cooper, C., Seely, D., Kanfer, I. (2005). African herbal medicines in the treatment of HIV: Hypoxis and Sutherlandia. An overview of evidence and pharmacology. Nutr. J. 4: 19.

14. Minuzzo, S., Monerle, L., Indraccolo, S., Amadori, A. (2007). Angiogenesis meets immunology: cytokine gene therapy of cancer. Mol. Asp. Med. 28: 59-86.

15. Parkin, J., Cohen, B. (2000). An overview of the immune system (review). Lancet 357: 1777-1789.

16. Rios, J-L. (2010). Effects of triterpenes on the immune system. J. Ethnopharmacol. 128:1-4.

17. Salazar-Onfray, F., Lopez, M.N., Mendoza-Naranjo, A. (2007). Paradoxical effects of cytokines in tumour immune surveillance and tumour immune escape. Cytokine Growth Factor Rev. 18: 171-182.

18. Sia, C. (2004). Spotlight on ethnomedicine: Usability of Sutherlandia frutescens in the treatment of diabetes. Rev. Diabet. Stud. 1: 145-149.

19. Stander, B.A., Marias, S., Stivaktas, V., Vorster, C., Albrecht, C., Lottering, M-L., and Joubert, A.M. (2009). In vitro effects of Sutherlandia frutescens water extracts on cell numbers, morphology, cell cycle progression and cell death in a tumorigenic and a non-tumorigenic epitheial breast cell line. J. Ethnopharmacol. 124: 45-50.

20. Stander, B.A., Marias, S., Steynberg, T.J., Theron, D., Joubert, F., Albrecht, C., Joubert, A.M. (2007). Influence of Sutherlandia frutescens extracts on cell numbers, morphology and gene expression in MCF-7 cells. J. Ethnopharmacol. 112: 312-318.

21. Tai, J., Cheung, S., Chan, E., Hasman, D. (2004). In vitro culture studies of Sutherlandia frutescens on human tumour cell lines. J. Ethnopharmacol. 93: 9-19.

22. Van Wyk, B.E., Albrecht, C. (2008). A review of the taxonomy, ethnobotany, chemistry and pharmacology of Sutherlandia frutescens (Fabaceae). J. Ethnopharmacol. 119: 620-629.

23. van Wyk, B.E., van Oudtshoorn, B., Gericke, N. (1997). Medicinal plants of South Africa, $2^{\text {nd }}$ edition. Briza Publications, Pretoria.

24. van Wyk, B.E. (2008). A broad review of commercially important southern African medicinal plants. J. Ethnopharmacol. 119: 342-355. 